\title{
ASSESSMENT OF OCCUPATIONAL HEALTH AND SAFETY SYSTEM IN LATVIA
}

\author{
M. EGLITE ${ }^{1}$, I. VANADZINS ${ }^{1}$, L. MATISANE ${ }^{2}$, M.A. BAKE ${ }^{1}$, D. SPRUDZA ${ }^{1}$, Z. MARTINSONE ${ }^{1}$, \\ I. MARTINSONE ${ }^{1}$, I. KALVE ${ }^{3}$, J. RESTE ${ }^{1}$, J. CIRULE$^{1} \&$ A. SEILE ${ }^{1}$ \\ ${ }^{1}$ Institute of Occupational Safety and Environmental Health of Riga Stradins University, Latvia. \\ ${ }^{2}$ Inspecta Prevention, Latvia. \\ ${ }^{3}$ Department of Occupational and Environmental Medicine of Riga Stradins University, Latvia.
}

\begin{abstract}
The aim of this study was to analyse working conditions and occupational morbidity in order to assess development of occupational health and safety (OHS) system in Latvia during the last 15 years. Analysis of database on workplace risk factor measurements (provided by Laboratory of Hygiene and Occupational diseases) from more than 7000 workplaces, carried out during 1995-2010, was also provided. The results revealed that occupational risk factor values exceeded the recommended limits for one third of the measurements. The traditional work risk factors (chemical, physical, biological, etc.) have been partly replaced by new risks (ergonomic and psychosocial factors). Results of the study indicated that the main risk group for non-compliance with legislation, regarding OHS, is comprised by small and medium companies from private and non-governmental sector and from companies working in industries, such as construction, metal processing and wood processing. The study reveals poor knowledge and evaluation of OHS issues both by employees and employers. The study also shows a direct correlation between a good working environment, and the company's efficiency and sustainability in general. Statistical data shows that the number of firstly diagnosed occupational diseases and patients has gradually increased. The total number of firstly diagnosed and registered occupational patients per 100000 employees was 11.2 in 1995 and 140.5 in 2009. The structure of occupational diseases reveals that musculoskeletal diseases (46.1\%) comprise the leading group of diseases followed by diseases of the nervous system and organs of sense (29.3\%), traumatic disorders and intoxications (11.7\%).

Keywords: occupational health and safety, occupational health system, occupational morbidity, occupational risk factors, structure of occupational diseases.
\end{abstract}

\section{INTRODUCTION}

A rapidly changing living environment is closely linked to changes in the work environment: work becomes more intense and requires maximum attention and concentration, adaptation to work, mental and physical capacity of an individual, as well as dealing with different managerial issues [1]. Occupational risk factors could be observed in all economic sectors and can affect large number of employees. Work as such, is an important part of human life as it ensures our independence and social contacts, and affects our mental and physical health. However, the working environment has a significant impact on the biological processes in the human body, and can directly affect the safety, health and work ability of an employee [2]. The health consequences of occupational risk factors, new technologies and unknown effects of existing technologies provide reason for concern among the working population and experts involved in organisation of work and healthcare. The occurrence of non-specific health effects is often the first indication of occupational risks. Most problems that occur at the workplace can be prevented by improving health and welfare of employees and work productivity and general economic indicators (WHO, 1995). It is impossible to ensure the work environment without any risk factors; therefore, reduction and control of risks is a major responsibility for every employer. Designing and implementation of preventive measures to improve working conditions should be evaluated considering the level of the 
occupational risks, financial resources of the company and suitability of the proposed measures. Adequate control and risk reduction to acceptable levels can be implemented only if employers, their experts, as well as employees are aware of the nature of the occupational risk and can forecast its probable effects.

The aim of the study is to analyse work conditions, occupational morbidity and assessment of occupational health system in Latvia within the recent 15-year period, in order to characterise the general situation in occupational health and safety (OHS) system in Latvia and to work out recommendations for necessary changes in OHS policy.

\section{MATERIALS AND METHODS}

The database of measurements of occupational risk factors in more than 7000 enterprises and companies, performed in the period 1995-2010 by the Laboratory of Hygiene and Occupational diseases of the Institute of Occupational Safety and Environmental Health of Riga Stradins University was analysed. The Laboratory is accredited for measurements of occupational risk factors according to LVS EN ISO/IEC17025. The database comprises the assessment of 11 physical risk factors and various chemical factors in 30082 workplaces.

The following risk factors were most frequently measured:

- the noise level was measured in 4480 workplaces (according to four different parameters: $8 \mathrm{~h}$ mean equivalent noise level, maximum noise, peak sound pressure, equivalent noise level);

- whole-body vibration: measurements were carried out in 1145 workplaces and hand-arm vibration measurements in 582 workplaces;

- microclimate (indoor air) evaluation, including ventilation, was performed in 11483 workplaces (four different parameters: relative air humidity in 3729 workplaces, air temperature in 3782 workplaces, air velocity in 36505 workplaces, ventilation in 322 premises);

- lighting: in 12392 workplaces.

The database also contains wide-ranging information on chemical substances - altogether 93 chemical substances (e.g., organic solvents in varnish, paint, synthetic detergents) - and aerosols of dust (e.g., welding fumes, abrasive dust, wood dust), measurements of which were carried out in more than 5000 workplaces. Various standards based on ISO methods and modern measuring equipment were used, such as detection of concentration of solvents and organic compounds in working environment using gas chromatograph Varian 3800 with FID and ECD detectors, and measurements of metals using atomic absorption spectrophotometer (Varian Spectra AA) with graphite furnace and electro-thermal atomisation with Zeeman background correction.

Organic solvent measurements were made in 2679 workplaces in the breathing zone of workers, using devices for taking individual samples. The measurements of occupational exposure to organic solvents were carried out in 290 companies of 22 various sectors of economy (company codes according to NACE classification) [3]. To get more representative information, the measurements of occupational exposure to 30 organic solvents, included in the database, were analysed combining them into eight groups, based on similar structure: aromatic hydrocarbons, summary hydrocarbons, esters, ketones, petroleum distillates, celosolves, halogen hydrocarbons and alcohols.

To assess the probability of a health risk, caused by the occupational exposure to chemical factors in working environment, the exposure index (EI) is used, which shows the degree of 
occupational exposure to a chemical substance and at the same time provides information on the probability of the effect of a chemical substance on the workers' health [according to EN 689]. The exposure index is determined relating the existing concentration of a chemical substance in the working environment to the occupational exposure limit value, determined by legislation for each substance (OEL). By applying the exposure index one can carry out the assessment of joint exposure risk of different chemical substances, irrespective of their individual numerical values.

The exposure indexes of chemical substances with low, medium and high exposure degrees are divided into three groups/classes. The first group with the exposure index less than or equal to 0.1 shows a low exposure probability of chemical substances. The second group $(0.1<\mathrm{EI} \leq 0.75)$ shows a medium exposure probability. The third group $(\mathrm{EI}>0.75)$ reflects a high exposure probability.

The following risk factors were also assessed: biologic factors (e.g., organisms causing tick-borne encephalitis, viral hepatitis B and C, HIV/AIDS); mechanic factors (e.g., work with an equipment and with a dangerous equipment, work at height, work in an explosive atmosphere); ergonomic factors (e.g., awkward posture, repetitive movements, lifting of heavy objects); psychosocial factors (e.g., shortage of time, overtime work, work at night, bad relationships with superiors and colleagues, conflicts).

Several smaller surveys were carried out in the framework of the survey, e.g., "Work conditions and risks in Latvia" in 2010, namely for group of 1044 employers, 2505 employees and 210 OHS specialists. Questions were related to working conditions and occupational risks within enterprises. Computerised interviews (Computer Assisted Telephone Interviews $(C A T I))$ and specialised ad hoc interviews were used for employers. For employees, direct computerised interviews (Computer Assisted Personal Interviews (CAPI)) at the respondent's place of residence, and specialised employees' ad hoc interviews were used. For OHS specialists electronically distributed self-addressed interviews were used. A special sub-survey was developed for each group of respondents; however, all questionnaires contained an identical general part. This enabled us to analyse occupational risks, working conditions, legal labour relations, awareness and other topics per each group, and compare the results. Apart from that, each group had to answer specific questions, for example, employers and their representatives were asked about the quality of training in OHS (160-hour training programme, compulsory for the company staff providing OHS services in their companies), persons with special needs - on their chances in the labour market, on working conditions, etc. The following questions were included in all surveys: awareness of working conditions and occupational risks, special aspects of working conditions and occupational risks, working conditions within the respective enterprise, including working time (overtime work, time for work and time for relaxation, reduced working hours, etc.), compliance with legal labour relations in the enterprise, conclusion of employment contracts, compliance with OHS legislation within the enterprise (on-site training and instructions, use of the individual protective equipment, etc.), possible obstacles, problems, causing non-compliance with OHS requirements (economic and legislative problems, lack of knowledge or information, etc.), attitude towards occupational safety and its importance within the enterprise, employment contract options, available in the labour market (e.g., reduced working hours), representatives of employees regarding OHS issues (e.g., trusted representatives and/or membership in trade unions), etc.

Analysis of the registered occupational diseases according to the data from the Latvian State Registry of Occupational Diseases run by Centre of Occupational and Radiation Medicine of Pauls Stradins Clinical University Hospital for the same period was made. 
The term "occupational disease" in Latvia, is defined as follows: Occupational diseases are diseases characteristic to certain categories of employees, which are caused by physical, chemical, hygienic, biological and psychological factors in the working environment. Occupational diseases in Latvia are diagnosed and coded in accordance with the International Classification of Diseases. The currently used classification in Latvia is the $43^{\text {rd }}$ International Statistical classification of Diseases and related Health Problems (ISC-10), confirmed with the decree No. 20 on January 17, 1996 by the Ministry of Welfare of the Republic of Latvia. This classification has been adopted in Latvia without modifications, which allows for comparison between countries.

The absolute numbers of the first time registered occupational diseases patients as well as the absolute number of initially registered occupational diseases were analysed. In order to characterise the rate of cases of occupational diseases in dynamics, the sickness incidence ratio was used - cumulative incidence (CI). It is a quotient which is calculated according to the following equation: $\mathrm{CI}=$ the number of persons suffering from occupational diseases as a first-time occurrence within 1 calendar year/100000 of the employed in Latvia at the beginning of the year. Absolute numbers of new cases of occupational diseases were recalculated per 100000 employees for adequate comparison of occupational morbidity in Latvia with that of other EU Member States.

The statistical processing of the study results was implemented by employing SPSS 14.0 software (company SPSS Ltd., USA). In the statistical data analyses, adequate methods were used [4].

\section{RESULTS}

\subsection{Analysis of database of measurements}

Analysis of measurement database of the Hygiene and Occupational Diseases Laboratory of the Institute of Occupational and Environmental Health of Riga Stradins University helped us to assess compliance of the measured values with mandatory or recommended standards summarised in Fig. 1. As mentioned above, more than one third of the measured values of most occupational risks exceeded mandatory or recommended limits (norms or OEL) set by national legislation. These data were obtained by analysing the results of measurements done and calculating the percentage of those results exceeding the limit values. According to the database of work environment measurements improper indoor air quality (inappropriate air temperature, too low or too high relative to air humidity, as well as too low or too high air movement) should be considered as the most problematic issue. Bad microclimate (indoor air) itself causes neither occupational diseases nor workplace accidents; however, it negatively affects subjective conditions and the work ability of employees, thus decreasing quantity and quality of the performed job and could aggravate already prevalent diseases. For example, draught can worsen the course of musculoskeletal disorders. Inappropriate microclimate is mostly found in offices with bad air exchange and insufficient ventilation, outdoors in sheltered and semi-sheltered workplaces, as well as in workshops having draught. Another essential occupational risk according to the database is dust, especially abrasive dust caused by abrasive tools (e.g., cutting or polishing equipment) and welding fumes.

More than a third of analysis of physical factors - vibration (36\%), noise (44\%) and lightening (46\%) - do not comply with the corresponding mandatory or recommended values (Fig. 1) set by national legislation. 


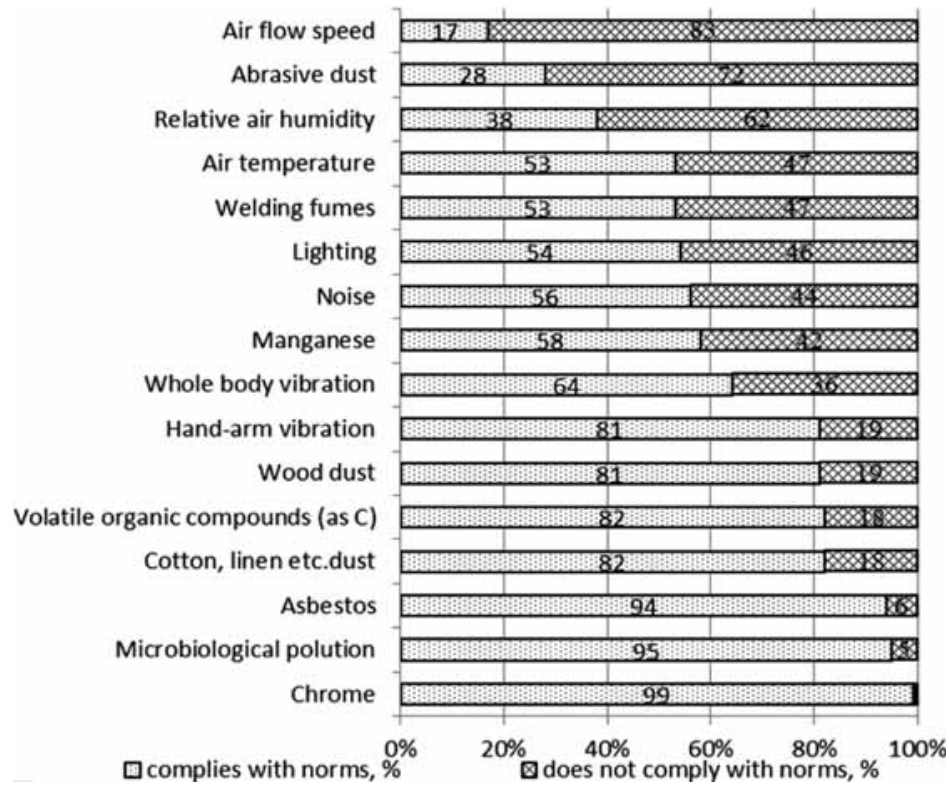

Figure 1: Compliance of occupational risk factors with norms or recommended standards (\% of carried out measurements) in Latvia in the period 1995-2009.

The results of measurements of organic solvent groups showed that toluene, xylenes and benzene were the most common pollutants (47\% of measurements) in work places. The most common alcohols from measurements performed were isopropanol, butanol and ethanol. In the 240 measurements of esters butyl acetate, ethyl acetate and methyl acrylate were predominating. The petroleum distillates were represented mostly by white spirit (lackbensin) or ligroin (a saturated hydrocarbon petroleum fraction) found in 195 measurements. 75\% of all measured halogenated hydrocarbons in working environments, were perchloroethylene in dry cleaning offices.

Analyses of the results of occupational exposure measurements of organic solvents carried out in different sectors according to NACE classification expressed by exposure indexes are presented in Table 1.

The highest level of exposure indexes was revealed in the following branches: leather processing and production of leather articles (74\%), public, social and individual services (dry cleaning $-70 \%)$, manufacturing of equipment, mechanisms and machine tools (29\%).

The current research data in Latvia shows that the traditional work risk factors (chemical, physical, biological) have been partly replaced by new risks (ergonomic, e.g. handling of heavy objects, awkward postures, work with a computer, repetitive movements; psychosocial factors, e.g., shortage of time, overtime work, long working hours, conflicts) [5] as working conditions continue to change from traditional industries towards office work and service sector. The analysis revealed that improper indoor air quality also should be considered as a significant occupational problem. Results of the study indicated that the following enterprises form a risk group of non-compliance with legislation regarding OHS: small enterprises, enterprises of private and non-governmental sectors, enterprises of different industries (construction, metal processing and wood processing). 
Table 1: Occupational exposure measurements (\%) of organic solvents carried out in various sectors of economy (company codes according to NACE classification) expressed by classes of exposure indexes (EI).

\begin{tabular}{|c|c|c|c|c|}
\hline \multirow{2}{*}{$\begin{array}{l}\text { NACE } \\
\text { code }\end{array}$} & \multirow[b]{2}{*}{ Type of economic activity } & \multicolumn{3}{|c|}{$\begin{array}{l}\text { Number of measurements by } \\
\text { classes of EI }(\%)\end{array}$} \\
\hline & & Low & Medium & High \\
\hline A & Forestry, timber preparation and related services & 60 & 40 & 0 \\
\hline DA & Food stuff, beverage and tobacco production & 50 & 50 & 0 \\
\hline DB & Textiles production & 100 & 0 & 0 \\
\hline DC & $\begin{array}{l}\text { Leather processing and production of leather } \\
\text { articles }\end{array}$ & 26 & 0 & 74 \\
\hline DD & Production of timber and wood articles & 61 & 35 & 4 \\
\hline $\mathrm{DE}$ & Publishing and printing industry & 65 & 23 & 12 \\
\hline DG & $\begin{array}{l}\text { Production of chemical substances and chemical } \\
\text { fibres }\end{array}$ & 68 & 28 & 4 \\
\hline $\mathrm{DH}$ & Production of rubber and plastic material articles & 40 & 34 & 26 \\
\hline DI & Production of non-metallic mineral articles & 100 & 0 & 0 \\
\hline DJ & Production of metal and metal articles & 59 & 30 & 11 \\
\hline DK & $\begin{array}{l}\text { Manufacturing of equipment, mechanisms and } \\
\text { machine tools }\end{array}$ & 28 & 43 & 29 \\
\hline DL & Manufacturing of electric and optical equipment & 62 & 19 & 19 \\
\hline $\mathrm{DN}$ & Furniture production & 71 & 22 & 7 \\
\hline $\mathrm{E}$ & Power, gas and water supply & 56 & 25 & 19 \\
\hline $\mathrm{F}$ & Construction & 50 & 27 & 23 \\
\hline $\mathrm{G}$ & $\begin{array}{l}\text { Repair of motorcars, motorcycles, household } \\
\text { equipment and devices }\end{array}$ & 57 & 22 & 21 \\
\hline I & Transport, rescue and communication & 48 & 29 & 23 \\
\hline $\mathrm{J}$ & Financial mediation & 0 & 100 & 0 \\
\hline $\mathrm{K}$ & $\begin{array}{l}\text { Real estate transactions, lease, computer services, } \\
\text { science and other commercial services }\end{array}$ & 75 & 18 & 7 \\
\hline $\mathrm{L}$ & $\begin{array}{l}\text { Public administration and defence; mandatory } \\
\text { social insurance }\end{array}$ & 75 & 18 & 7 \\
\hline $\mathrm{N}$ & Health and social care & 59 & 28 & 13 \\
\hline $\mathrm{O}$ & Public, social and individual services & 20 & 10 & 70 \\
\hline
\end{tabular}

3.2 Analysis of survey of employers, employees and occupational health and safety specialists

The Labour Protection Law came into force already on January 1, 2002 followed by subordinated legislation that came into force at the same time or little later. The new legislation was expected to significantly improve OHS situation in Latvia - primarily due to a major shift in approach to OHS. Formerly all efforts were aimed at mitigating the effects of poor working conditions (additional payments/additional days of paid holidays/free milk, etc.). The current 
system places the main emphasis on assessment, reduction or removal of occupational risk factors before the work starts and health effects that may occur. Therefore the survey of employees also included a question on how the OHS conditions have recently changed in their workplaces. Comparing the results of the study "Work conditions and risks in Latvia" in 2006 and 2010 with the study "Working Life Barometer in the Baltic countries" in 1998 and 2002, we can conclude that, in Latvia, the scope of improvements of workers' protection during the first years after the adoption of Labour Protection Law was approximately at the same level as in 1998 and 2002. However, the situation in 2010 changed. The number of respondents, who believe that the level of work protection has improved, decreased approximately three times. Generally, in 2010 only $5.9 \%$ of the respondents replied that the work protection improved (as compared with 2006 when $18.9 \%$ of all respondents indicated that OHS conditions at their work place improved during the last year). On the other hand, the number of employees who think that their job protection level has deteriorated has increased. It indicates that initially the working environment was improving rapidly (due to adoption of new legislation and other efforts), but recently the development of work protection is not as fast as before - most probably because of changing economic situation in the country (Fig. 2).

According to the requirements set by the Cabinet of Ministers Regulation No. 660 of October 6, 2007 "Procedures for the Performance of Internal Surveillance of the Working Environment", an employer, taking into account occupational risk assessment results and information obtained during inspection of workplaces, shall define OHS measures for prevention or mitigation of identified occupational risks, as well as define deadlines and responsible persons for implementation of such measures (in other words - to prepare the action plan). Therefore during the study, the employers, who declared that occupational risk assessment is fully or partially carried out in their enterprises, were asked if there was a programme of preventive measures (action plan) for improvement of the working environment and risk mitigation. Only $65 \%$ of the employers answered that they had prepared such action plan (increase by $15 \%$ as compared with 2006). According to researchers' experience, it is most unlikely that $35 \%$ of the companies, included in the survey, have a work environment not requiring any improvements; thereby we can assume that occupational risk assessments made for these companies are formal.

\section{The changes of occupational health and safety level}
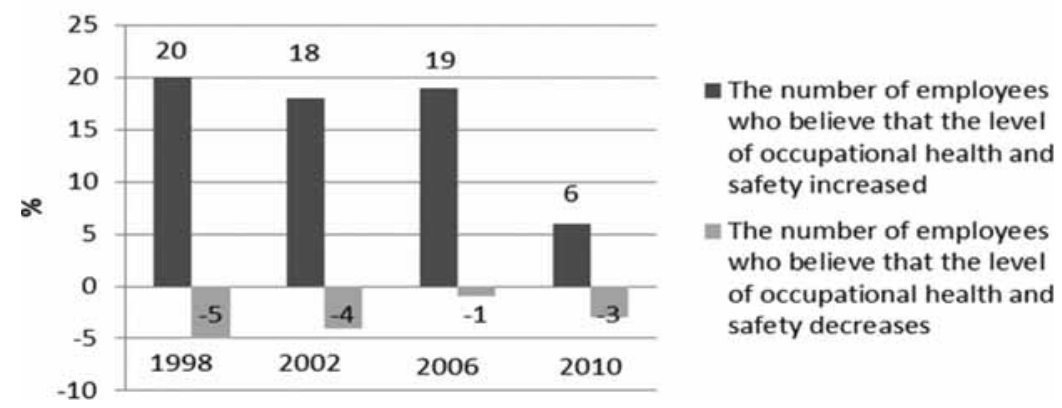
who believe that the level of occupational health and safety increased

En The number of employees who believe that the level of occupational health and safety decreases

Figure 2: The changes of occupational health and safety level in Latvia (\%) in the period 1998-2010 as perceived by employees. 
According to the survey data, in practice there is quite a gap between the larger companies, and small and medium sized companies (SME). Only 24\% of the companies with 1-10 workers and $61 \%$ of the companies with 11-49 employees made risk assessment in 2010, which is a far better performance than in 2006 (13\% and $49 \%$ respectively), but still it means that only a quarter of the companies in Latvia have done risk assessments. Further analysis shows that the situation is worse in smaller enterprises $-59 \%$ of the companies having 2-5 employees and $43 \%$ of the companies employing 6-10 workers had not done a risk assessment, while the situation improves with the size of the company.

$49.5 \%$ of all surveyed employers admitted that there were obstacles for carrying out OHS measures in their company (enterprise), but $50.4 \%$ declared that there were no obstacles for implementation of such measures.

As the most frequent obstacle for taking the necessary labour protection measures in their own company, employers have mentioned the lack of resources $(25.9 \%)$. Another frequently mentioned reasons for this were: there is no need or sense to do it - it was mentioned by $7.6 \%$ of respondents, lack of time $-7.3 \%$ of the respondents, lack of information (claim ignorance) and the fact that OHS requirements are unreasonable $-4.1 \%$ of respondents.

Another interesting finding was that $24 \%$ of employers in 2010 and $43 \%$ of employers in 2006 stated that none of the employees was exposed to occupational risk factors (Fig. 3). Such finding shows that the employers are often unaware of what occupational risks mean, and that every single worker is exposed to some risks at their workplace even if the exposure levels are low.

\subsection{Occupational morbidity}

The system for listing of occupational diseases and their registration, developed in 1997, improved in 2006. The system for health surveillance was established in 1997, adjusted in 2004 and significantly improved in 2009. Training of occupational physicians has improved since 1996 (e.g. from 50 hours to 500 hours), resulting in increase of registered occupational diseases. The number of certified occupational physicians has increased recently, as well as

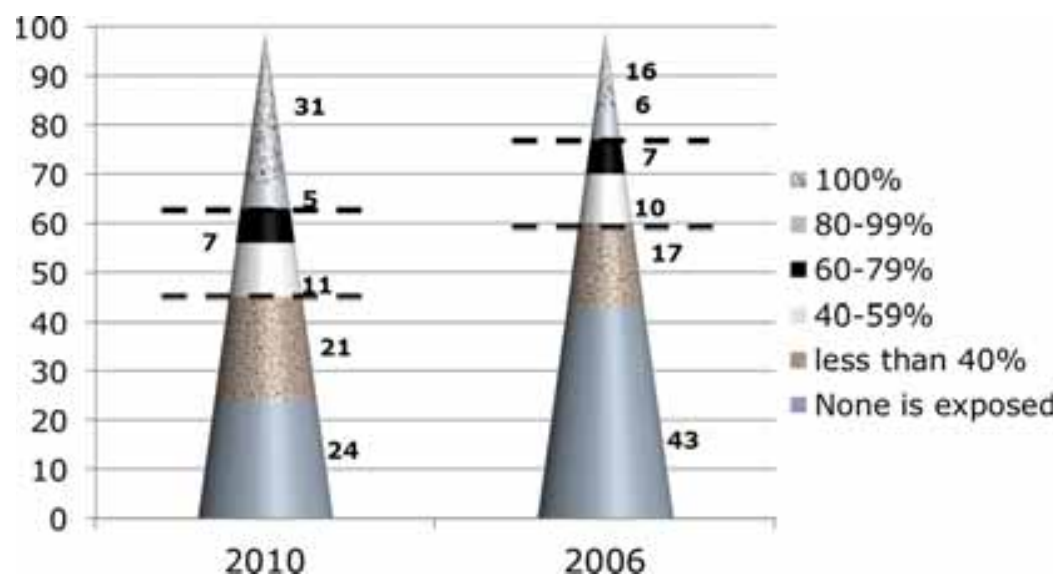

Figure 3: Employers answers to "How many (\%) of your employees are exposed to any occupational risk factors at workplace?". 
the number of compulsory health examinations to be carried out. There are 449 occupational physicians in Latvia (01.01.2011.) - 47 per 100000 employees. A majority of occupational doctors are members of Latvian Society of Occupational Physicians (LSOP).

Dynamics of morbidity with occupational diseases in Latvia during the period from 1996 to 2010, characterises the general situation in OHS system in Latvia.

The number of occupational diseases and patients per year gradually increased in the period 1996-2009. The total number of firstly diagnosed and registered occupational patients per 100000 of employees was 11.2 in 1996 and 138.6 in 2009 (Fig. 4).

The number of first time patients in 2009 exceeded that of 1993 by 12 times, but the number of first time diagnosis by 14.8 times. In 2010 there was a slight decrease in occupational morbidity due to organisational reasons and changes in registration system.

In Latvia, chronic forms of occupational diseases are most common. On very rare occasions acute or sub-acute cases of occupational diseases or chronic occupational diseases in the initial stages have been recorded.

In Latvia, quite often one occupational patient may have several occupational diseases caused by different occupational risks. For example, a carpenter may suffer from loss of hearing due to noise exposure and a respiratory disease due to dust exposure. Mean number of occupational diseases per person was 2.5 in 2010.

Structure of occupational diseases in 2009 shows musculoskeletal diseases (46.1\%) as the leading group of diseases, followed by diseases of nervous system and organs of sense $(29.3 \%)$ and traumatic disorders and intoxications (11.7\%).

Similarly to situation worldwide, the structure of occupational diseases in Latvia changed during 1993-2010. Since 1999 there has been an increase in morbidity of diseases caused by physical overloads, such as musculoskeletal and connective tissue disorders, as well as carpal tunnel syndrome, but occurrence of occupational diseases caused by chemical substances and dust has decreased. Structure and dynamics of occupational diseases per 100000 employees in 1997-2009 are shown in Table 2.

In Latvia, musculoskeletal and connective tissue disorders (ICD-10 code M00-M90) and carpal tunnel syndrome (ICD-10 code G560) are included in the list of occupational diseases caused by physical overloads (several types of so-called ergonomic problems, including lifting of heavy objects, awkward postures, repetitive movements, etc.).

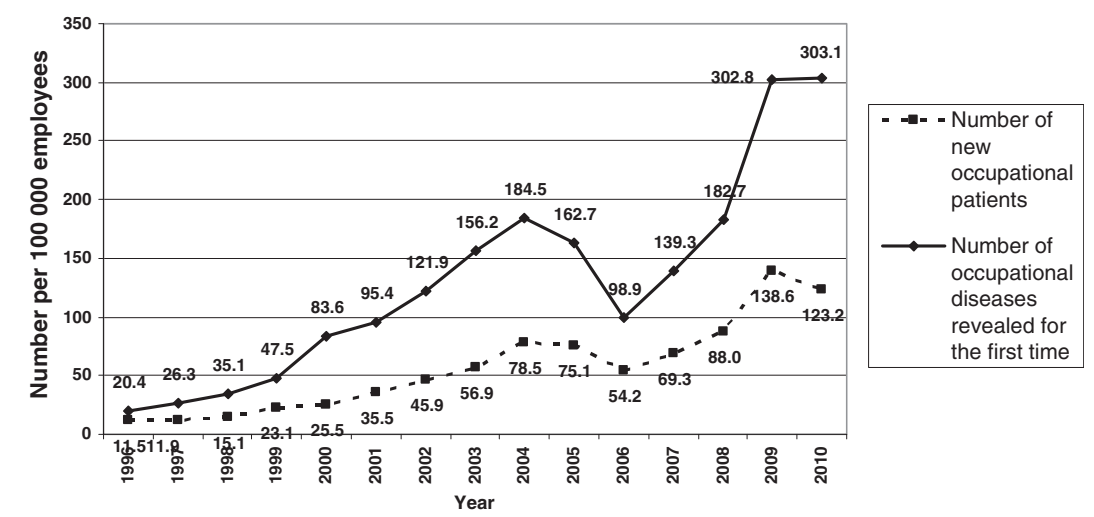

Figure 4: Total number of first-time registered occupational diseases patients and occupational diseases in Latvia during 1996-2010 per 100000 employees. 
Table 2: Structure and dynamics of occupational diseases per 100000 employees in 1997-2009.

\begin{tabular}{lcrrr}
\hline & 1997 & 2001 & 2005 & 2009 \\
\hline Spondylosis with radiculopathy & 1,7 & 24,7 & 46,9 & 92,1 \\
Carpal tunnel syndrome & 1,7 & 11,1 & 28,8 & 55,2 \\
Vibration impact & 2,6 & 4,2 & 16,7 & 33,4 \\
Occupational hearing loss & 0,5 & 3,1 & 12,1 & 30,9 \\
Arthrosis & 0,2 & 7,4 & 25,1 & 17,8 \\
Chronic inflammatory upper airway diseases & 0,1 & 7,5 & 7,2 & 15,8 \\
Asthma & 1,0 & 2,1 & 3,0 & 7,0 \\
Chronic inflammatory lung diseases & 3,2 & 5,0 & 2,1 & 3,9 \\
Polyneuropathy caused for other toxic factors & 2,9 & 3,6 & 1,3 & 0,1 \\
Lead and its compounds & 1,8 & 3,2 & 0,0 & 0,0 \\
\hline
\end{tabular}

\section{DISCUSSION}

Latvian system for OHS is on no account different from the majority of the EU countries since it has been aligned with the EU Framework directive (89/391/EEC) and other EU directives concerning health and safety at work. There are naturally small differences based on historical traditions and other factors, such as economical situation, insurance systems, etc. [8].

There is a traditional opinion that in Latvian enterprises conventional occupational health problems, such as noise, vibration, dust, chemical substances, etc., prevail, while the EU countries mostly deal with psychosocial, managerial and ergonomic risks. The information obtained during the study reveals that at present, psychosocial factors and ergonomic factors are among the most essential occupation risk factors in Latvia, too. It means that conventional risk factors are substituted by modern ones. On the other hand, laboratory analysis shows that microclimate and dust (especially abrasive dust and welding fumes) should still be considered as significant occupational problems. Taking into account that psychosocial and ergonomic risk factors, as well as microclimate, usually interfere with each other and often intensify the effects of each other, this group of factors should be treated with great care $[1,6,7]$.

Measurements of the work environment are not carried out frequently enough. As a result, in most cases occupational risk assessment cannot be considered as being objective. Results of the study showed that work environment measurement values exceed mandatory or recommended limit values in one third of cases. It could be explained by the fact that measurements are not carried out in all workplaces, but only in those requested by the company itself (for example, an employer, a competent specialist or authority) and thus the most "dangerous" or "hazardous" workplaces are selected.

The number of occupational diseases and patients, diagnosed for the first time per year gradually increased in the period 1993-2010. This is only partly related to the current working environment. A number of currently revealed health problems are still associated with exposure to occupational risk factors during the last 10-15 years. Supposedly, during the next 5 to 10 years the number of occupational diseases proceeds to grow, reaching 250 cases per 100,000 employees, then stabilisation and even a gradual slight decrease are expected. In addition, breakdown of occupational diseases by types has changed. At present musculoskeletal 
diseases are the most frequently diagnosed occupational diseases, comprising approximately one half of all registered diseases. This group of diseases requires special attention; therefore, it is necessary to build employers' awareness of ergonomic risks in work environment.

The Latvian State Occupational Diseases Registry mainly contains chronic forms of occupational diseases which have developed within many years and do not correlate with exposure duration. Therefore it can be assumed that increase in occupational morbidity in Latvia is related not only to working conditions but to other factors too. One of the other factors could be the following - many years occupational morbidity in Latvia was lower than that of other EU states; therefore, it is probable that due to improved diagnosis and registration of occupational diseases the number of cases registered for the first time will still grow. However, considering amendments in legislation, it is hard to forecast onset and speed of such increase in future.

Musculoskeletal diseases are a particular issue and, according to the data of the Centre of Occupational and Radiation Medicine of Pauls Stradins Clinical Hospital, they belong to the most frequently found occupational disorders in Latvia. One should remember that musculoskeletal diseases are the so-called "painful diseases" which often have only short-term effects on working ability. On the other hand, the study reveals that ergonomic risk factors, which cause musculoskeletal problems, prevail in the working environment.

Occupational morbidity in Latvia is considered coherent to the occupational morbidity registered in other European countries. It should be noted that during the recent years occupation morbidity tends to decrease in the developed EU countries, while it is still increasing in Latvia. Working conditions in the European Union, in general, are improving and correspondingly lead to decreased occupational morbidity rates [9]. However, in Latvia, improved diagnosis of occupational diseases is still outpacing improvement of working conditions.

The results of the study indicate that there is a need to improve OHS legislation, as well as the system for interpretation of such legal requirements and building of public awareness. Too low numbers of employers and employees are informed on legal requirements, as well as on their responsibilities and rights.

\section{CONCLUSIONS}

1. Results of measurements showed that one third of the measured risk factor values exceed mandatory or recommended limits, but the situation has improved in recent years. The results of surveys reveal insufficient assessment of risk factors in workplaces and selection of most hazardous or common ones only. Occupational risk assessment is frequently carried out formally and disregarding the legal requirements.

2. The traditional occupational risk factors (physical, chemical, biological) have been replaced by new risks (psychosocial - shortage of time, overtime work, long working hours; ergonomic - work with a computer, handling of heavy objects, awkward posture, and repetitive movements, microclimatic, etc.) in Latvia today.

3. The situation in Latvia, regarding completion of occupational risk assessment and compliance of such assessment with the requirements of existing legislation, has slightly improved compared to that of 2002. However, it is still rather bad and cannot be recognised as being good in small enterprises, enterprises of private and non-governmental sectors, and enterprises of different industries.

4. The registered number of occupational diseases has been on the increase during the last 15 years, from 11.2 cases per 100000 employees in 1995 to 140.5 in 2009, which may 
be explained by successful change of the registration system and investments in training of doctors and experts.

5. Early diagnosis of occupational diseases during compulsory medical examinations is essential. This will reduce necessity for compensations from the state insurance for workplace accidents to be paid in case of permanent loss of work ability. To facilitate returning of employees into labour market after recovering from occupational illnesses, the focus should be switched to effective rehabilitation.

6. In general, although the situation in Latvian occupational safety and protection system within the last five years has slowly and gradually improved, it is still not satisfactory.

\section{REFERENCES}

[1] Eglite, M., Vanadzins, I., Matisane, L., Bake, M.B., Sprudza, D., Martinsone, Z., Martinsone, I., Reste, J., Cirule, J. \& Seile, A., Work conditions and occupational morbidity in Latvia. Environmental Health and Biomedicine, eds. C.A. Brebbia, M. Eglite, I. Knets, R. Miftahov \& V. Popov, WIT Press: UK, pp. 221-232, 2011. doi: http://dx.doi.org/10.2495/EHR110201

[2] Darba apstākḷi un riski Latvija 2009-2010. Latvijās Darba devēju konfederācija: Riga, 122 lpp, 2010. Electronic publications/pdf. http://osha.lv/lv/research

[3] Kauppinen, T., Hanhela, R., Heikkilä, P., Kasvio, A., Lehtinen, S., Lindström, K., Toikkanen, J. \& Tossavainen, A., Work and Health in Finland. In: Changes in Work and Working Conditions in 1997-2006, 2006. available at http://www.ttl.fi/Internet/English/ Information/Electronic publications/pdf.

[4] Riedman, A., Bielenski, H., Szczurowska, T. \& Wagner, A., European Foundation for the Improvement of Living and Working Conditions. Working Time and Work Life Balance in European companies: Dublin, p. 70, 2006.

[5] Work conditions and risks in Latvia. Republic of Latvia, Ministry of Welfare: Riga, p. 146, 2007. Electronic publications/pdf, available at http://www.inspecta.lv/docs/ work_conditions_and_risks_in_latvia.pdf/.

[6] Glossary:Statistical classification of economic activities in the European Community (NACE) http://epp.eurostat.ec.europa.eu/statistics_explained/index.php

[7] Altman, D.G., Practical Statistics for Medical Research. Chapman and Hall: London, p. 606, 2003.

[8] Rantanen, J., Kauppinen, T., Lehtinen, S., Mattila, M., Toikkanen, J., Kurpa, K., Leino, T., Work and Health Country Profiles of Twenty Two European Countries. Finish Institute of Occupational Health: Helsinki, p. 444, 2002.

[9] Rantanen, J., Kauppinen, T., Toikkanen, J., Kurpa, K., Lehtinen, S. \& Leino, T., Work and health country profiles and national surveillance indicators in occupational health and safety, In: People and Work. Research Reports 44. Finish Institute of Occupational Health: Helsinki, 2001. 